\title{
SPEEDING UP ROBOT MANIPULATORS WITH ELASTIC JOINTS
}

\author{
Salem Samak \\ Prod. Eng. and Mech. Design Department \\ Faculty of Engineering \\ El-Menoufiya University \\ Shebin El-Kom, EGYPT
}

\author{
Bilal Maher \\ Basic Eng. Sciences Department \\ Faculty of Engineering \\ El-Menoufiya University \\ Shebin El-Kom, EGYPT
}

\begin{abstract}
The dynamic formulations of manipulators lead to a set of highly nonlinear and strongly coupled differential equations which represents the dynamic model of a manipulator. Beside many other forces, this model describes the actuator forces (or torques) which cause the manipulator joints to move. In this paper, manipulator joints are modeled as elastic springs with joint stiffness in order to impose elastic forces to the dynamic system model and to monitor their influences when speeding up the manipulator end-effector. The kinematic relationships are described by using the zero-reference-position method. Both the inverse and direct dynamics problems are developed by applying Kane's dynamical equations as an analytical tool. A Stanford-type manipulator is considered as a numerical example. The implications of the results are monitored, compared and justified.
\end{abstract}

\section{KEYWORDS}

Manipulators, Robotics, Joint Stiffness, Joint Elasticity, Precision.

\section{INTRODUCTION}

In robot performance, the discrepancy always exists between the actual and the desired position and orientation of a robot end-effector. Some of these discrepancies due to variations in robot kinematic parameters resulting from tolerances in robot manufacturing and assembling; while others due to joint drive compliance between the angular encoder and the actual angular output. Due to the complexity of the dynamic equations of motion for $n$-link manipulators with joint elasticity, most researchers have relied on computer programs to generate those equations.

\footnotetext{
Manuscript received from Dr. SALEM SAMAK on : 1/12/1999

Accepted on : 22/3/2000

Engineering Research Bulletin, Vol 23,No 2, 2000 Minufiya University, Faculty of Engineering, Shebien El-Kom, Egypt, ISSN. 1110-1180
} 
Kuo and Sanger [1] modeled redundant manipulator joints as elastic springs with joint stiffness in order to select a desired or specified joint configuration. Spong [2] studied the dynamics of a manipulator with elastic joints by utilizing a nonlinear feedback control. In this paper, the actuator force at each joint is modeled by an elastic spring. The influence of increasing the joints stiffness with speeding up the end-effector task on the performance of positioning and orienting the end-effector precision is monitored. The analysis is carried out for a six degrees-of-freedom Stanford-type manipulator. However, All formulations are devoted to general manipulators. They do not prone to specific configuration or dimensions.

\section{KINEMATICS ANALYSIS}

The kinematic relationships between the links are described by using the zeroreference-position (ZRP) method. This method was introduced by Gupta [3]. It has the advantages that it is not prone to the discontinuity difficulties as those in the Denavit Hartenberg notation. Due to the nature of this method, small changes in the structure inherently correspond to small changes in the structure parameters. It has also proven its effectiveness and versatility in many works on both kinematic and dynamic analysis of robot manipulators $[4],[5],[6],[7]$ and [8]. The joint coordinate systems in this method are not used. Instead, a convenient reference position of the robot is chosen and the following vectors are defined in the world coordinate system (Fig. 1).

$\boldsymbol{u}_{0 i} \Rightarrow$ a unit vector along joint axis i.

$b_{0 i} \Rightarrow$ a body vector which connects a point on joint (i-1) to a point on joint $\mathrm{i}$.

$\boldsymbol{u}_{0 a}$ and $\boldsymbol{u}_{0 t} \Rightarrow$ two perpendicular vectors fixed on the end-effector.

All the above mentioned parameters are given in their zero reference position (with zero subscript). They are converted to the current position as the manipulator moves. The current vector are derived from their zero-reference-position vectors as follows [4]

$$
\begin{gathered}
u_{i}=\left(2 E_{o, i+1}^{2}-1\right) u_{o i}+2\left(E_{i+1} \cdot u_{o i}\right) E_{i+1}+2 E_{o, i+I}\left(E_{i+1} \times u_{o i}\right) \\
b_{i}=\left(2 E_{o i}^{2}-1\right) b_{o i}+2\left(E_{i} \cdot b_{o i}\right) E_{i}+2 E_{o i}\left(E_{i} \times b_{o i}\right)
\end{gathered}
$$

Where $E_{0 i}, E_{0, i+1}, E_{i}$ and $\boldsymbol{E}_{i+1}$ are derived from the Euler-Rodrigues parameters and Rodrigues composition formula. These formulas eliminate the inefficiency due to the use of the regular rotation matrices.

\section{MODELING}

The dynamical equ-ations lead to a set of highly nonlinear and strongly coupled differential eq-uations which represents the dynamic model of a manipulator. In a six degrees-of-freedom manipulator, the equations of motion is the time rate of change of its linkage configuration in relation to the external torques at the 
gripper and those exerted by the actuators. In the inverse dynamics problem, the time history of the required joint actions (external forces and/or torques) are obtained. Whereas,

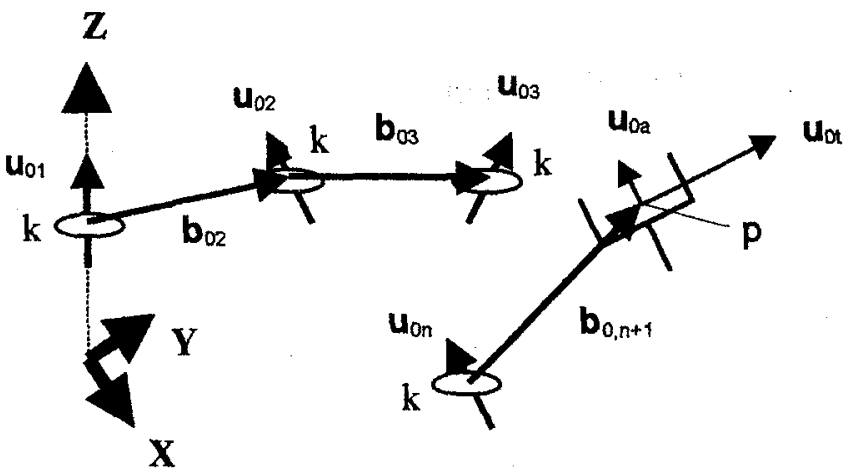

Fig. 1. Zero reference position notation with an elastic spring at each joint

in direct dynamics

problem (simulation), the joint motion is computed when the joint forces and/or torques are given as functions of time. It is an important tool in the design and testing of manipulators or their control schemes. Both the inverse and direct dynamics problems are developed by using Kane's dynamical equations. The advantage of this method is that it eliminates the nonworking interactive forces between links. It also facilitates the generation of dynamic equations in an explicit and computationally efficient form [7]

$$
H(q) \dot{S}+C\left(q, s_{i} s_{j}\right)+G(q)=f
$$

where $\boldsymbol{H}(q)$ is an $\mathrm{n} \times \mathrm{n}$ symmetric, non-singular inertia matrix, $\boldsymbol{C}\left(\boldsymbol{q}, s_{i} s_{j}\right)$ is an $\mathrm{n} \times 1$ vector of centrifugal and Coriolis effects, $\boldsymbol{G}(\boldsymbol{q})$ is an $\mathrm{n} \times 1$ vector of gravity force and end-effector loading, and $f$ is an $n \times 1$ vector of actuator forces (or torques) and the elastic forces or (torques).

$S$ represents the generalized speeds. They are quantities intimately associated with the system motion, rather than merely with its configuration. They are also used to take advantage of special features of a given physical system. They can be introduced as follows:

$$
s_{r}=\sum_{r=I}^{N} \gamma_{r s}+v_{r} \quad ; \mathrm{r}=1,2, \ldots, \mathrm{n}
$$

where $\gamma_{\mathrm{rs}}$ and $v_{\mathrm{r}}$ are functions of the joint variables $\left(\mathrm{q}_{1}, \mathrm{q}_{2}, \ldots, \mathrm{q}_{\mathrm{n}}\right)$ and time $(\mathrm{t})$. The generalized speeds could be chosen to be simply $\boldsymbol{S}=\dot{\boldsymbol{q}}$, and hence $\dot{\boldsymbol{S}}=\ddot{\boldsymbol{q}}$. However, they can be also chosen to be the angular velocity measure numbers; or the linear velocity measure numbers

In this paper, the analysis is performed as follows: First, during the computer simulation, the actuator force at each joint is modeled by an elastic spring. i.e., a torsional spring for revolute joint or a rectilinear spring for prismatic joint. As the manipulator moves, the joint configuration is changed from its initial value $\boldsymbol{q}_{o}$ to the current value $\boldsymbol{q}_{c}$. As a consequence of joint stiffness, there exists a stiffness force $Q$ applied at each joint. It can be expressed as follows 


$$
Q=k\left(q_{c}-q_{o}\right)
$$

where $\mathrm{k}$ is the stiffness constant. Even though different stiffness constant can be used at each joint, only one value is used for all joints in this paper. Second, a trajectory is assigned in such a way that it can perform its task with different end-effector trajectory speeds. This is done by gradually increasing the manipulator trajectory execution time. As a result, the influence of increasing the joint stiffness with speeding up the end-effector task on the performance of positioning and orienting the end-effector precision is monitored.

\section{A NUMERICAL EXAMPLE}

A six degrees-of-freedom Stanford-type manipulator, which contains five revolute joints and one prismatic joint, is considered. A trajectory is chosen in such a way that the end-effector remains tangent to a conincal surface. A point $p$ at the end-effector moves on a circle of radius 5 inches in a cycloidal function profiles at the beginning and the end of its motion. The trajectory execution time are selected to be 3,6 and 9 seconds. The joint stiffness constants $(\mathrm{k})$ variations are $0,0.005,0.010 .015$ and 0.02 . Table 1 represents the maximum rotational and positional deviations with increasing the joint stiffness and task executing time.

Table 1 Maximum rotational and positional deviations with increasing the joint stiffness and task executing time

\begin{tabular}{ccccccc}
\hline Stiffness & \multicolumn{2}{c}{$\mathrm{t}=3$} & \multicolumn{2}{c}{$\mathrm{t}=6$} & \multicolumn{2}{c}{$\mathrm{t}=9$} \\
\hline $\mathrm{k}$ & Rot. & Pos. & Rot. & Pos. & Rot. & Pos. \\
\hline \hline 0 & $0.36 \mathrm{E}-12$ & $0.69 \mathrm{E}-11$ & $0.65 \mathrm{E}-14$ & $0.69 \mathrm{E}-13$ & $0.36 \mathrm{E}-14$ & $0.49 \mathrm{E}-14$ \\
0.005 & $0.15 \mathrm{E}-8$ & $0.14 \mathrm{E}-7$ & $0.54 \mathrm{E}-9$ & $0.36 \mathrm{E}-8$ & $0.28 \mathrm{E}-9$ & $0.14 \mathrm{E}-8$ \\
0.01 & $0.58 \mathrm{E}-8$ & $0.55 \mathrm{E}-7$ & $0.22 \mathrm{E}-8$ & $0.14 \mathrm{E}-7$ & $0.11 \mathrm{E}-8$ & $0.56 \mathrm{E}-8$ \\
0.015 & $0.13 \mathrm{E}-7$ & $0.12 \mathrm{E}-6$ & $0.49 \mathrm{E}-8$ & $0.33 \mathrm{E}-7$ & $0.25 \mathrm{E}-8$ & $0.13 \mathrm{E}-7$ \\
0.02 & $0.23 \mathrm{E}-7$ & $0.22 \mathrm{E}-6$ & $0.87 \mathrm{E}-8$ & $0.58 \mathrm{E}-7$ & $0.45 \mathrm{E}-8$ & $0.22 \mathrm{E}-7$ \\
\hline
\end{tabular}

Figure 2 shows high degree of trajectory tracking precision for zero joints stiffness. The precision increases monotonously with speeding up the end-effector. On the other hand, they increase moderately for other joints stiffness. In this case, the precision trajectory tracking decreases as the stiffness constants (k's) are increased. Figure 3 represents the local rotational and positional deviations when the trajectory execution time are 3 and 6 seconds. Whereas, Fig. 4 represents the local rotational and positional deviations when the trajectory execution time is 9 seconds. From the shown figures, the trajectory tracking precision is higher in local rotational deviations than those in local positional deviations. Moreover, both Figs. 3 and 4 show that speeding up the execution time leads to more oscillatory behavior which, as a consequent, tends to improve the precision in the trajectory execution. 

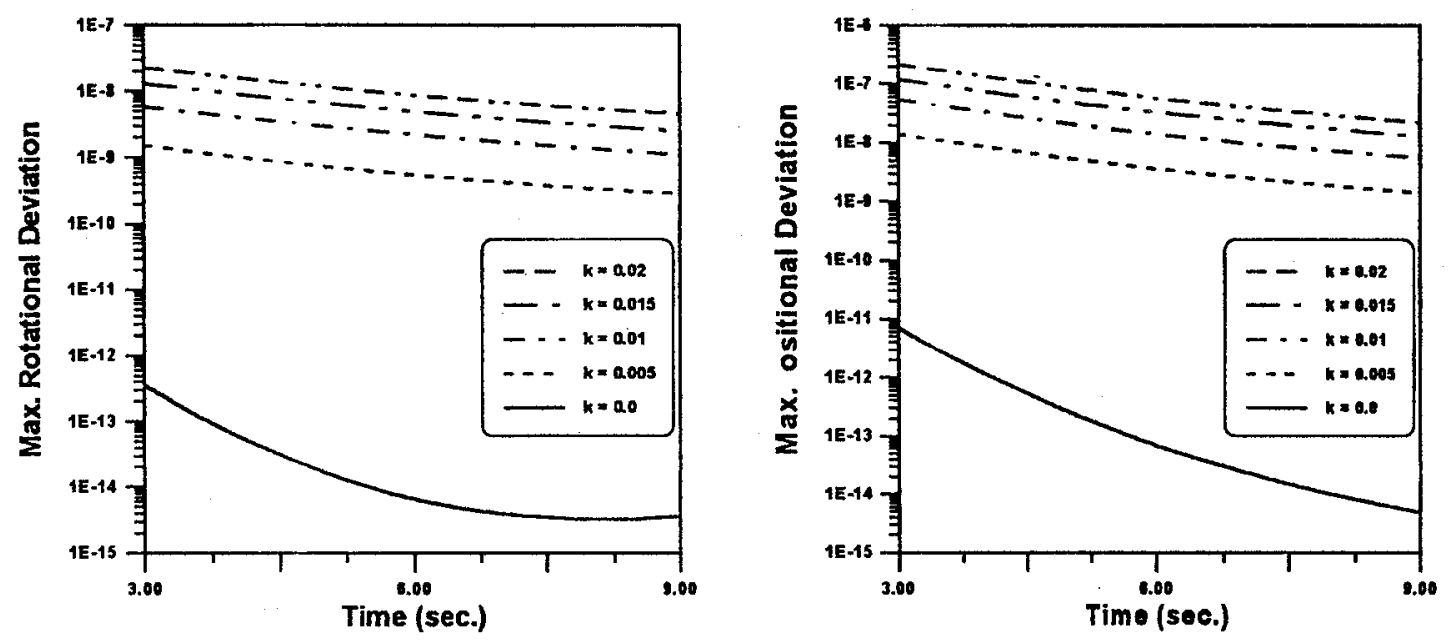

Fig. 2. Maximum rotation and positional deviations for different joint stiffness values versus time
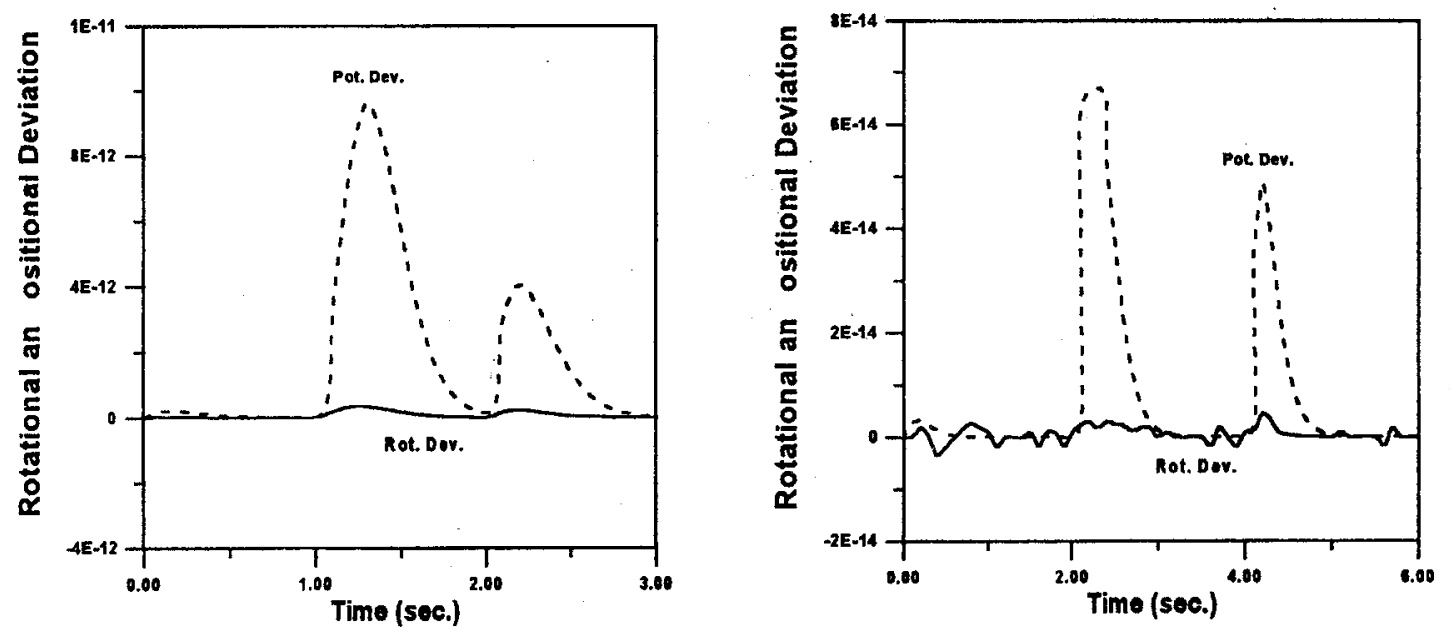

Fig. 3. Local rotational and positional deviations for $\mathrm{t}=3$ and $6 \mathrm{sec}$.

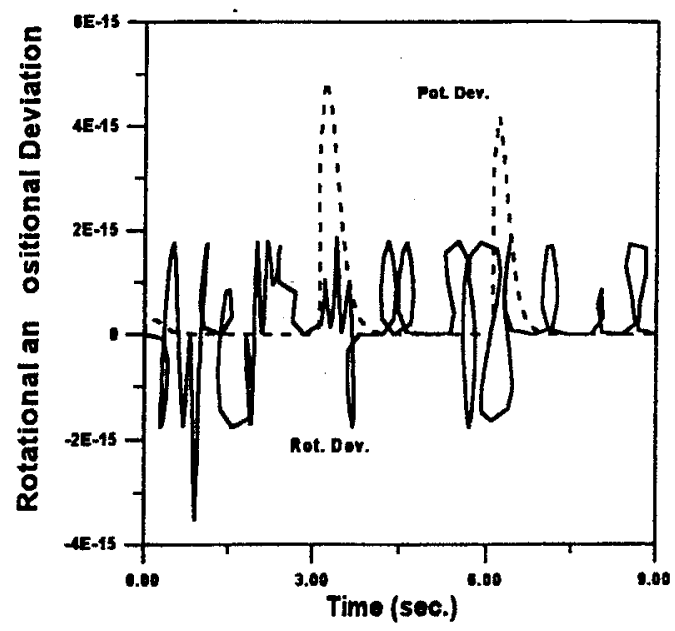

Fig. 4. Local rotational and positional deviations for $t=9 \mathrm{sec}$. 


\section{CONCLUSIONS}

The kinematics relationships are developed by utilizing the zero-referenceposition method. Whereas, both the inverse and direct dynamic problems are developed based on Kane's dynamical equations. All formulations are devoted to general manipulators. The influence of increasing the joint stiffness with speeding up the end-effector task is monitored to investigate the performance of positioning and orienting the end-effector precision. The analysis has been conducted for a Stanford-type manipulator. It shows high degree of trajectory tracking precision for zero joints stiffness. On the other hand, the maximum rotational and positional deviations increases monotonously with speeding up the end-effector. It also shows the trajectory tracking precision is higher in local rotational deviations than those in local positional deviations. Finally, speeding up the execution time leads to more oscillatory behavior which tends to improve the precision in the trajectory execution.

\section{REFERENCES}

[1] Kuo, J.A. and Sanger, D.J., "Effect of Joint Configuration on Required Joint Stiffness for Kinematically Redundant Manipulators", IFToMM $9^{\text {th }}$ World Congress on the Theory of Machines and Mechanisms, Milano, Italy, Vol. 3, pp. 1866-1870, 1995.

[2] Spong, M.W. "Modeling and Control of Elastic Joint Robots", ASME Journal of Dynamic Systems, Measurement, and Control, Vol.109, pp. 310 $318,1987$.

[3] Gupta, K.C., "A Note on Position Analysis of Manipulators". Proceeding $7^{\text {th }}$ Applied Mechanisms Conference, Kansas City Vol. 3, pp. 1-3, 1981; also Mechanism and Machine Theory, Vol. 19, pp. 5-8, 1984.

[4] Gupta, K.C and Singh, V.K., "A Numerical Algorithm for Solving Robot Inverse Kinematics", Robotica, Vol. 7, pp. 159-164, 1989.

[5] Samak, S., El-Sayed, S., El-Shakery, S. and El-Dardierie, M., "Kinematic Perturbations on Robot Precision", 7 th IFToMM International Symposium on the Theory of Machines and Mechanisms, Bucharest, Romania, , Vol. 2, pp. 327-332, 1997.

[6] Samak, S.M. and Gupta, K.C., "Effect of Dynamic Model Errors on Robot Precision", 21 st ASME Mechanism Conference, Chicago, USA, pp. 73-79, 1990.

[7] Samak, S.M. and Gupta, K.C., "Parametric Uncertainty on Manipulators Dynamics", Mechanism and Machine Theory, Vol. 33 No. 7, pp. 945-956, 1998.

[8] Gupta, K.C., "Mechanics and Control of Robots", Springer, New York, 1997. 


\section{تَنْيع مناولات إنسان آلي ذات مفاصل مرنة}

$$
\begin{aligned}
& \text { د. بلال ماهر } \\
& \text { كسم العلوم الهنسية الاسلسية } \\
& \text { كلية الهنسة - جامعة المنوفية }
\end{aligned}
$$

\author{
د. ســالم ســك \\ كسم هنسة الاثتاج والتصميم الميكانيكى لهي \\ كلية الهنسة - جامعة النوفية الهية
}

ملثص البحث بالمغة البعيية

الصنياغات الديناميكية التى تمثل النموذج الديناميكى للمناو لات تؤول إلِى مجموعة

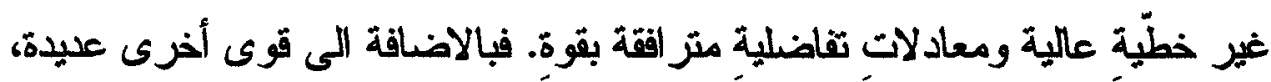

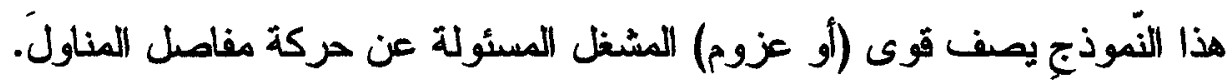

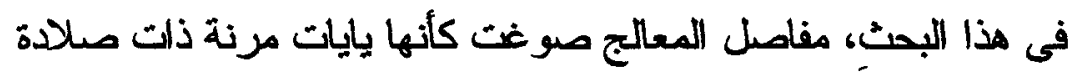
(stiffness) تأثير هم عند تسريع النهاية الطرفية (end-effector) للمعالج. العالقات

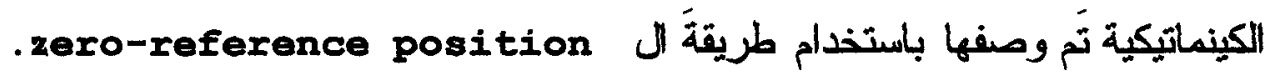
كلا من مشكلة الديناميكا المعكوسة (inverse Dynamics problem)

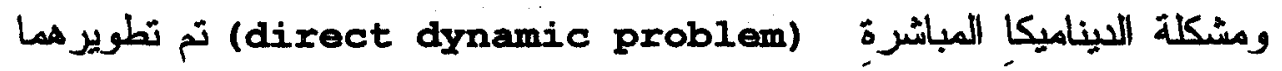
(Rane's dynamical equations) باستخدام معادلات كين التيناميكية كأداة تحليلية. معالج من نوع ستانفورد (Stanford-type manipulator)

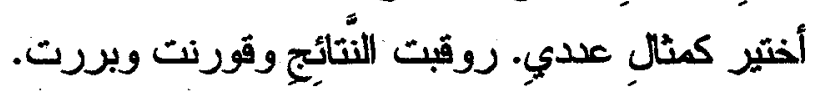

